\title{
IMAGENS, DESENHOS E SIGNIFICADOS DE PROFESSORES E ALUNOS COM NECESSIDADES EDUCATIVAS ESPECIAIS EM ESCOLAS COM EDUCAÇÃO INCLUSIVA $^{1}$
}

\section{O Desenho como Ferramenta de Integração Social na Educação Inclusiva²}

\author{
Janaí de Abreu Pereira ${ }^{3}$; Neli Klix Freitas ${ }^{4}$
}

Palavras-Chave: Arte-educação - socio-interacionismo - necessidades educativas especiais.

Resumo - Partindo da abordagem historico-cultural de Vygotsky, dialogamos com as implicações para o debate sobre a educação inclusiva na escola, na arte-educação e na sociedade, levando em conta a complexidade que caracteriza o processo de ensino-aprendizagem e o desenvolvimento infantil. A educação para a diversidade é considerada fundamental para que a inclusão possa realmente acontecer.

Cumprir o dever de incluir todas as crianças na escola regular, supõe uma reavaliação de todo o sistema educacional e extrapola a simples inovação educacional. Implica no reconhecimento de que o outro é sempre diferente, a diferença é a regra e não a exceção. A educação inclusiva tem conseguido seu espaço após inúmeras pressões sociopolíticas, econômicas e educativas. Atualmente temos inúmeras medidas legislativas, tais como: Constituição Federal (1988), Estatuto da Criança e do Adolescente (1990), Lei de Diretrizes e Bases da Educação Nacional - Lei n.9394/96, Declaração de Salamanca (1994), Convenção Interamericana (1999) entre outras, que atestam o direito dos portadores de necessidades educativas especiais (PNEE), de freqüentarem as instituições regulares de ensino, independentemente de suas condições físicas, cognitivas, sensoriais, origem sócio-econômica, étnica ou religiosa. Isso implica na conquista de um novo espaço social . No decorrer da história, os PNEE eram isolados do convívio social, submetidos algumas vezes a torturas, abandono e maus tratos.

A Declaração de Salamanca (1994) atesta que todas as crianças devem aprender juntas, independentemente de suas dificuldades ou diferenças, ou seja este aprender juntas, leva em

\footnotetext{
${ }^{1}$ Projeto de Pesquisa CEART/UDESC

${ }^{2}$ Subtítulo da pesquisa

${ }^{3}$ Orientadora, Docente do Departamento de Artes Plásticas - Centro de Artes - Av Madre Benvenuta, 1907, Itacorubi, Florianópolis/SC.

${ }^{4}$ Discente do Curso de Licenciatura em Artes Plásticas - CEART/UDESC, bolsista de iniciação científica do PIBIC/CNPq.

DAPesquisa, Florianópolis, v.2, n.4, p. 338-344, 2007.
} 
consideração o contexto social, histórico e cultural em que estão inseridas. A idéia do ser humano imerso num contexto histórico, enquanto “[...] corpo e mente, enquanto ser biológico e social, [...] membro da espécie humana e participante de um processo histórico" (OLIVEIRA, 2005, p.23). Isso coincide com a concepção histórico-cultural ou socio-interacionista, com ênfase nas contribuições de Lev Semenovich Vygotsky.

Profundamente influenciado pelas teorias marxistas, das premissas do método dialético, afirma que as origens das atividades psicológicas mais sofisticadas do ser humano acabam se formando nas relações sociais, na relação indivíduo/sociedade/cultura. O mesmo não é somente um produto do meio, mas um agente ativo na criação e modificação do meio em que está inserido. Enfatiza o papel da linguagem e da aprendizagem nesse desenvolvimento. Sua questão central é a aquisição do conhecimento em interação social. Assim, resulta que "[...] ao mesmo tempo em que o ser humano transforma o seu meio para atender suas necessidades básicas, transforma-se a si mesmo" (REGO, 2004, p.41). As funções psicológicas especificamente humanas, como a percepção, a imaginação, as representações mentais se originam na interação das relações do indivíduo com o seu contexto cultural e social.

A importância que Vygotsky dá ao papel do outro social baseia-se em que "[...] o aprendizado e desenvolvimento estão inter-relacionados desde o primeiro dia de vida da criança" (VYGOTSKY, 2003a, p.110). Existe um processo de desenvolvimento em parte definido por um processo de maturação do organismo biológico individual, e em parte realizado no aprendizado social e cultural.

Existem, pelo menos dois níveis de desenvolvimento identificados por Vygotsky: um denominado real, onde o desenvolvimento das funções mentais da criança, já foi adquirido e refere-se ao que ela consegue fazer sozinha; e um potencial, ou seja, a capacidade de aprender com outra pessoa. A aprendizagem interage desta maneira com o desenvolvimento, e a distância entre estes dois níveis produz o que Vygotsky (2003) denomina de zona de desenvolvimento proximal.

Esta potencialidade para aprender não é a mesma para todas as pessoas, ou seja, a distância entre o nível de desenvolvimento real e o nível de desenvolvimento potencial, é singular e único. É na interação social que ocorre o processo de construção das funções psicológicas humanas. Levando em consideração este aspecto é que o ambiente educacional regular pode contribuir significativamente para o processo de aprendizagem. Esta inserção possibilita a troca de experiências, a socialização, tendo como finalidade o desenvolvimento dos PNEE, em seus aspectos físicos, psicológicos, intelectuais, emocionais e socias, construindo neste ambiente de diversidade um campo privilegiado da experiência educativa. Segundo Vygotsky, esta interação com o mundo ocorre por meio de mediações, 
ou seja não é uma relação direta, mas uma relação mediada, sendo os sistemas simbólicos os elementos intermediários entre o sujeito e o mundo, “[...] a analogia básica entre signo e instrumento repousa na função mediadora que os caracteriza" (VYGOTSKY, 2003a, p.71).

Poderíamos pensar no conceito de mediação de Vygostky (2003a) relacionando a arte como sendo mediadora no processo sócio - histórico do desenvolvimento do ser humano enquanto sujeito do conhecimento, através da construção de representações da realidade, operado pelos sistemas simbólicos de que dispõe. Coloca-se ênfase na construção do conhecimento como uma interação mediada por várias relações, ou seja, o conhecimento não está sendo visto como uma ação do sujeito sobre a realidade mas, pela mediação feita por outros sujeitos ou objetos. O outro social, pode apresentar-se por meio de objetos, da organização do ambiente, do mundo cultural que rodeia o indivíduo. Segundo Vygostky (2003a), a atividade criadora é uma manifestação exclusiva do ser humano, pois só este tem a capacidade de criar algo novo a partir do que já existe, levando em consideração a memória. O homem pode imaginar situações futuras e formar outras imagens a partir das imagens com que ele interage. A ação criadora desta forma residiria na não-adaptação do ser, que se constitui como tal, em uma constante construção.

Nesta pesquisa foram coletados, analisados e interpretados dados de trinta professores e dez alunos com necessidades educativas especiais como sujeitos da educação inclusiva. O método empregado de análise dos dados foi a Análise de Conteúdo, segundo Bardin (1977). Aos participantes da pesquisa, crianças com necessidades educativas especiais, foi solicitado que participassem, executando visualidades (desenho, pintura, colagem e outros), em uma série de dez, e relatassem o significado atribuído às mesmas, falando sobre o que realizaram. Todos os dados foram coletados em escolas públicas. Entende-se esta atividade como processo, a criança cria e interpreta as visualidades, ressaltando sobretudo a linguagem verbal, nunca como algo terminado, pronto "[...]o processo da atividade gráfica é permeado por interações entre as crianças, por momentos de emergência de jogo simbólico e isso não aparece no desenho finalizado" (FERREIRA; SILVA, 2001, p.147). Consiste numa produção gráfica e estética, que é socialmente constituída, é a exteriorização de uma maneira de ver o mundo. Não se originam do nada, mas da interação que a criança tem com seu meio social, que integra-se com a linguagem, na visão de Vygotsky (2001), de imagem mais palavra, no processo de atribuição de significados.

Levando em consideração a teoria histórico-cultural de Vygotsky, para que a criança realize tais atividades é necessário um amadurecimento nas áreas neuromotora, socioafetiva e cognitiva. Na arte faremos um recorte para o desenho, tendo em vista o número elevado deste apresentado na pesquisa. $\mathrm{O}$ DAPesquisa, Florianópolis, v.2, n.4, p. 338-344, 2007. 
desenho é um signo empregado pelo homem e é constituído nas interações sociais.

Edith Derdyk (2003) enfatiza um entendimento do ato de desenhar como atividade inteligente e sensível, reclama a sua autonomia e sua capacidade de abrangência como um meio de comunicação, expressão e conhecimento, possui a natureza aberta e processual.

Neste ato de desenhar está implícita uma conversa entre o pensar e o fazer. A percepção e a sensibilidade são as janelas para o mundo que possibilitam a troca permeável entre o que está dentro e o que está fora. Segundo Derdyk (2003, p.112) “[...] o desenho traduz uma visão porque traduz um pensamento, revela um conceito". Estão contidas referências do cotidiano, alusões à fantasia, lembranças, significações, interpretações, elaborando correspondências, relacionando, simbolizando, significando num jogo contínuo entre o real, o percebido e o imaginário.

No livro Imaginación y El Arte en la Infancia, Vygotsky (2003b), aborda que a constituição do homem se dá no plano da intersubjetividade. Enfatiza que a imaginação é uma atividade mental vinculada com a realidade que tem sentido e significado. A criança ao desenhar interpreta esta realidade, por meio da fantasia e da imaginação. Por isso, o enfoque da pesquisa se dá na fala da criança sobre sua visualidade, seu desenho. A fala é o signo fundamental que possibilita a ponte com o conhecimento de sentido subjetivo atribuído ao desenho. Portanto é o pensamento expresso através da fala da criança que explicita seu mundo, e não somente os traços, rabiscos e figurações que, sozinhos remetem a muitas interpretações.

A imaginação e a fantasia se alimentam do já existente, do vivido, do experienciado, da lembrança de vivências concretas. Desta forma, o desenho da criança está pautado na realidade conhecida por ela, criando outra realidade, com significados próprios. Segundo o autor a imaginação não se limita à reprodução de imagens historicamente constituídas, mas leva em consideração esta bagagem imagética e cria novas combinações. Desenhando objetos reais, por exemplo, a criança expressa o significado e o sentido das coisas que vê, não é a realidade material do objeto, tal como ele é, mas sim uma realidade vista por sua lente, uma realidade conceituada, é essa a realidade percebida por ela, é o mundo dos significados.

Vygotsky (2003b) afirma que a criança não desenha o que vê, mas sim o que conhece. Referente a isso destaca o papel da mediação, seja pelos signos ou pelo outro social. O papel da mediação na teoria histórico-cultural tem inicío a partir do surgimento dos signos psicológicos. Uma nova força irá participar e alterar a constituição do sujeito, nas relações entre desenvolvimento e aprendizado, e estaria mais centrada nos fatores sociais do que nos biológicos. Qualquer função 
psicológica no desenvolvimento intelectual da criança aparece em dois momentos, primeiro no plano social, interpsicológica e logo depois no plano psicológico, intrapsicológica.

É na relação com o outro que a criança toma consciência de si mesma. Desta forma, ao trabalhar com visualidades das crianças com necessidades educativas especiais, nessa pesquisa são estes princípios norteadores. Quando o processo de produção das visualidades, traz à tona figurações, fantasias e imaginação, esses representam o real possível, elaborado pelas vivências da criança que é constituída socialmente, mediado através do signo verbal. O significado é auto- atribuído pelo autor da visualidade.A fala também é mediadora de outras atividades da criança, como o jogo e o brinquedo.

Como Vygotsky (2003b) relata, a imaginação depende da experiência. A riqueza do processo gráfico constitui-se através da fala, da motricidade e outros sinais corporais. No processo de coleta dos dados foi importante observar a interação da professora com os alunos, dos alunos entre si e com a pesquisadora. Por isso, o registro do momento da produção gráfica é importantíssimo, e não somente no produto final. É surpreendente verificar a dimensão sociocultural no grafismo, relações estabelecidas entre o pensamento e o real, mediada pela atividade simbólica e pela linguagem nas crianças com necessidades educativas especiais, em interação social nas escolas com educação inclusiva.

Pensar na escola inclusiva é pensar que estas visualidades são determinadas pelo contexto sócio-cultural, que ninguém pinta, desenha, ou molda aquilo que vê, mas o que aprendeu a ver. A importância da arte é expressiva no processo educativo de desenvolvimento e aprendizagem da criança como sujeito que se expressa e se insere no mundo, ampliando repertórios e somando experiências que irão alimentar seu imaginário. É possível identificar, na produção visual mediada por verbalizações, que as crianças mostram vivências familiares, gostam de mostrar seus trabalhos aos colegas, à professora. Diante da oportunidade de desenhar, o significado de expressar-se surge como estímulo para outras expressões compartilhadas. Essas questões resultaram da análise dos desenhos.

Quanto aos professores, na coleta de dados esses referiram-se a imagens do passado e do presente, relacionando a formação com o exercício atual da docência nas escolas com educação inclusiva. A interação social foi evidenciada, o que ocorreu tanto no material dos professores, quanto no dos alunos. Trata-se de uma evidência que corrobora o princípio básico proposto por Vygotsky.

Para a educação inclusiva o direito à diferença constitui um dos princípios fundamentais que sustentam um modelo de educação que visa à construção, pelos PNEE, de seus valores de forma racional e autônoma.

É uma possibilidade que se abre para o desenvolvimento e para o benefício de todos os alunos, DAPesquisa, Florianópolis, v.2, n.4, p. 338-344, 2007. 
com ou sem necessidades educativas especiais, nas escolas regulares de ensino, trazendo consigo um conjunto de fatores, para que todos possam ser inseridos totalmente na sociedade em todos os seus segmentos: trabalho, lazer, saúde, dentre outros.

A inclusão se concilia com uma educação para todos e com um ensino especializado ao aluno, mas não se consegue implementar uma opção de inserção tão revolucionária sem enfrentar um desafio ainda maior: o que recai sobre o fator humano. Os recursos físicos e os meios materiais para a efetivação de um processo inclusivo escolar de qualidade cedem um espaço de prioridade para o desenvolvimento de novas atitudes e formas de interação na escola, exigindo uma nova postura diante da aceitação e valorização das diferenças individuais, da convivência na diversidade humana, e da aprendizagem por meio da cooperação (FREITAS, 2006).

Um ensino que leva em conta a aprendizagem parte do princípio de que todos os alunos podem aprender alguns podem necessitar algumas adaptações curriculares, fruto da existência infinita de perfis de aprendizagem. Pensando na aprendizagem e nas dificuldades de aprendizagem é possível dialogar com os alunos com necessidades educativas especiais na própria escola para que todos tenham acesso ao conhecimento socialmente produzido. Este processo envolve o aluno, o docente, a escola, a família e a sociedade como parceiras.

Na perspectiva Vygotskiana, o ensino escolar desempenha um papel importante neste processo, e este aspecto ficou evidente nos dados já analisados. Cumpre salientar ainda que a pesquisa permitiu um contato direto com o processo da educação inclusiva como um todo, com os sujeitos envolvidos: professores e, no caso dos participantes, crianças com necessidades educativas especiais, mas também com o contexto escolar e familiar envolvidos neste processo. Vivenciar o conhecimento estabelecido nas mediações sociais, históricas e culturais, através dos relatos e visualidades dos mesmos possibilitou o acesso à compreensão dos aspectos positivos e negativos da educação inclusiva, do que deve ser melhorado.

A educação inclusiva, na perspectiva da pesquisa, volta o olhar para o coletivo, mas não homogêneo, por isso a arte é um meio de diálogo possível, porque parte de uma singularidade para a coletividade, traça este diálogo mediante a heterogeneidade humana, a valorização da diversidade, dos múltiplos olhares e sensibilizações, como um elemento enriquecedor do desenvolvimento pessoal e social. 


\section{Referências}

BARDIN, L. Analise de Conteúdo. Lisboa: Edições 70, 1977.

BRASIL. Lei de Diretrizes e Bases da Educação Nacional. Lei n. 9394, de 20 de dezembro de 1996. D.O.U.de dezembro de 1996. Florianópolis: Sindicato das Escolas Particulares de Santa Catarina, 1996.

BRASIL. Constituição da República Federativa do Brasil. São Paulo: Atlas, 1988.

BRASIL. Estatuto da Criança e do Adolescente. Lei n. 8069, de 13 de julho de 1990. CONVENÇÃO INTERAMERICANA PARA A ELIMINAÇÃO DE TODAS AS FORMAS DE DISCRIMINAÇÃO CONTRA AS PESSOAS PORTADORAS DE DEFICIÊNCIA. Assembléia Geral Vigésimo Nono Período Ordinário de Sessões, de 6 de junho de 1999. Disponível em : 〈www.mec.gov.br> acesso em 10/07/2007.

DECLARAÇÃO DE SALAMANCA E LINHA DE AÇÃO SOBRE NECESSIDADES EDUCATIVAS ESPECIAIS. Brasília: Corde, 1994.

DERDYK, E. Formas de Pensar o Desenho. São Paulo: Scipione, 2003.

FERREIRA, S ; SILVA, S. "Faz o Chão para Ela Não Ficar Voando": O Desenho na Sala de Aula. IN: FERREIRA, S (Org.) O Ensino das Artes - Construindo Caminhos. Campinas: Papirus, 2001.

FREITAS,N.K.Tramas Conceituais:Imagens e Significados em Arte e Educação. IN: Revista Teoria e Prática da Educação,Vol.10, UEM, 2006.

OLIVEIRA, M.K. Vygostky - Aprendizado e Desenvolvimento um processo sócio histórico. São Paulo: Ed. Scipione, 2005.

REGO, T.C. Vygotsky - Uma perspectiva histórico-cultural da educação. Petrópolis: Ed. Vozes, 2004.

VYGOTSKY, L.S. A Formação Social da Mente. São Paulo: Martins Fontes, 2003a.

VIGOTSKY, L.S. La Imaginación y El Arte en la Infancia. Madrid: Akal, 2003b.

VYGOTSKY, L.S. Psicologia da Arte. São Paulo: Martins Fontes, 2001. 